\title{
Pensando sobre o Uso das Tecnologias na Formação de Professores no Contexto EaD

\section{Paulo Sergio Schelesky ${ }^{1 \star}$}

Ana Lúcia Pereira ${ }^{1}$

Luciane Grossi ${ }^{1}$

1 Universidade Estadual de Ponta

Grossa. Av. General Carlos Cavalcanti,

4748 - Campus Uvaranas. Ponta

Grossa - Paraná.*

pauloschelesky@gmail.com

\section{Resumo}

Este artigo apresenta o resultado de uma pesquisa que tem como objetivo desvelar se, e como, os professores formados no contexto EaD se apropriam do uso das tecnologias digitais. A pesquisa é de natureza quanti-qualitativa e os dados foram coletados por meio de questionários eletrônicos e os sujeitos participantes foram 22 egressos do Curso de Licenciatura em Matemática na modalidade EaD de uma Universidade Estadual de Paraná. Os dados foram organizados e analisados por meio de Análise Textual Discursiva e Análise de Clusters de onde foi possível identificarmos dois clusters principais. Nossos resultados apontam que há indícios de incorporação do uso das tecnologias digitais na prática docente dos sujeitos do cluster 1. Acreditamos que isso foi evidenciado, principalmente, porque esses egressos iniciaram o curso de licenciatura com o desejo de ser professor e por exercerem o ofício da docência, ao contrário dos sujeitos do cluster 2 .

Palavras-chave: Formação de professores de matemática. Tecnologia. EaD. Habitus.

\section{क 0}

Recebido 19/ 06/ 2020 Aceito 14/ 12/ 2020 Publicado $18 / 12 / 2020$
COMO CITAR ESTE ARTIGO

ABNT: SCHELESKY, P. S.; PEREIRA. A. L.; GROSSI, L.. Pensando sobre o uso das Tecnologias na Formação de Professores no Contexto EaD. EaD em Foco, v. 10, n. 2, e1082, 2020. Doi: https:// doi.org/10.18264/eadf.v10i2.1082 


\title{
Thinking about the Use of Technologies in Teacher Education in the Learning Distance Context
}

\begin{abstract}
This article presents the result of a research that aims to reveal if, and how, teacher's education in the Distance Learning Context appropriate the use of digital technologies. The research is qualitative in nature and the data was collected through electronic questionnaires. The subjects are 22 teacher's education of mathematics, graduated in distance learning context at a State University of Paraná. The data were organized and analyzed by means of Discursive Textual Analysis and Cluster Analysis from where we were able to identify two main clusters. Nossos resultados apontam há indícios de incorporação do uso das tecnologias digitais na prática docente dos egressos do cluster 1. We believe that this has been evidenced mainly because these egresses began the degree course with the desire to be a teacher and for exercising the teaching profession, unlike the subjects of cluster 2 .
\end{abstract}

Keywords: Teacher education of mathematic. Technology. Distance learning context. Habitus.

\section{Introdução}

Nos últimos anos, temos presenciado o crescimento da Educação a Distância (EaD) no Brasil, impulsionado pelos avanços da internet e que vem se consolidando no cenário educacional brasileiro, não ficando restrita somente às instituições de ensino. Vemos inclusive, governos e empresas fazendo uso das potencialidades da EaD para capacitação pessoal.

Entretanto, a EaD é anterior à internet, com registros no Brasil que remetem ao fim do século XIX e início do século XX, com cursos oferecidos em material impresso via correio e mais tarde na década de 1920 com a utilização do rádio (ALVES, 2009). Essa época marca a primeira geração da EaD no Brasil, com o predomínio de material escrito; na segunda geração o uso da TV e na terceira geração é marcado pelos avanços da internet (ZABEL, ALMEIDA, 2015).

No contexto da terceira geração, há a criação da Universidade Aberta do Brasil (UAB) que se deu pelo decreto 5.800/2006, e que dispõe no Art. $1^{\circ}$ que "Fica instituído o Sistema Universidade Aberta do Brasil - UAB, voltado para o desenvolvimento da modalidade de educação a distância, com a finalidade de expandir e interiorizar a oferta de cursos e programas de educação superior no País" (BRASIL, 2006).

A principal característica da EaD refere-se à interação professor e aluno, em que ocorre a comunicação e construção do conhecimento, sem que estejam no mesmo espaço e tempo. Conforme no material produzido pelo $\mathrm{MEC}^{1}$, percebe-se a preocupação em considerar o aluno como centro do processo de aprendizagem e a interatividade (entre professores, tutores e estudantes) e a colaboração entre eles, destacando o papel das TIC nesse processo (BRASIL, 2007).

Portanto, no presente artigo, temos por objetivo apresentar o resultado de uma pesquisa que tem como objetivo desvelar se, e como, os professores formados no contexto EaD se apropriam do uso das

1 http://portal.mec.gov.br/seed/arquivos/pdf/legislacao/refead1.pdf 
tecnologias digitais. Os sujeitos da pesquisa são egressos do Curso de Licenciatura em Matemática da UEPG, na modalidade EaD, oferecido em parceria com o sistema UAB. Como opção de escrita, após essa introdução apresentamos algumas reflexões sobre a EaD como um campo de aprendizagem, fazendo algumas relações com conceitos de Bourdieu e Pierre Lévy; em seguida apresentamos o percurso metodológico, seguido pela apresentação dos nossos resultados e discussões. Por fim, tecemos as considerações finais, suscitadas a partir do estudo.

\section{Pensando na EaD como um campo de aprendizagem: um olhar a partir de Bourdieu e Pierre Lévy}

Nesta seção, apresentamos uma reflexão sobre a constituição de habitus tecnológico, a partir dos conceitos de Bourdieu (1996) e Lévy (1999). Acreditamos que o conhecimento de uma técnica não é suficiente para que o agente se aproprie dela, pois, como destaca Ponte (2000, p. 64), "toda técnica nova só é utilizada com desenvoltura e naturalidade no fim de um longo processo de apropriação".

Dessa forma buscamos investigar se os egressos se apropriam do uso das tecnologias digitais, de forma a caracterizar um habitus. Assim julgamos pertinentes os conceitos de Lévy (1999) como ciberespaço, cibercultura e inteligência coletiva e os conceitos de Bourdieu (1996), como capital cultural, campo e habitus.

O ciberespaço é o espaço criado a partir da interconexão dos computadores, mas além da estrutura material ele contempla as informações contidas nessa rede e também integra as mídias anteriores adicionando as melhorias da comunicação. O ciberespaço não configura um espaço geográfico, ele se constitui num universo de comunicação em rede por meio das tecnologias digitais, o ciberespaço modifica as estruturas sociais e a forma de compartilhamento e aquisição de saberes (LÉVY, 1999; LÉVY, 2000).

Considerando as características da terceira geração da EaD, marcada pela internet, entendemos que ela pode estar inserida e fazer uso das ferramentas comunicacionais e de aprendizagem do ciberespaço. Com o ciberespaço novas formas de comunicação são possíveis, mudando a percepção de vivência no tempo e espaço. Com isso, abre-se a possibilidade a aprendizagem coletiva em tempo real por meio dessa troca de informações, numa colaboração em rede, visto que uma representação no ciberespaço está, virtualmente, em todo lugar na rede (LEMOS, LÉVY, 2010; LÉVY, 2000).

Para Lévy (2015), "uma inteligência distribuída por toda parte" é tomada como um axioma da inteligência coletiva. O saber está na humanidade, todos sabem algo, ou seja, têm um saber para compartilhar, mas também ninguém sabe tudo, assim sempre terá algo a aprender. A partir do ciberespaço, podemos ter a interação de informações em tempo real; assim, é possível a construção de coletivos inteligentes, desenvolvendo habilidades sociais e cognitivas (LÉVY, 2015).

O autor enfatiza que o ciberespaço pode ser considerado como o "mediador essencial da inteligência coletiva da humanidade", serve como "suporte de informação e de comunicação", favorecendo que emerjam "gêneros de conhecimento inusitados, critérios de avaliação inéditos para orientar o saber, novos atores na produção e tratamento dos conhecimentos. Qualquer política de educação terá que levar isso em conta" (LÉVY, 1999, p. 166). No entanto, as ferramentas do ciberespaço na educação devem ser usadas de forma criteriosa, devido ao quantitativo de informações sem fonte confiável.

Neste ciberespaço defendido por Lévy, entendemos que é possível que a Educação a Distância ocorra, pois é definida como uma modalidade educacional na qual são utilizados "meios e tecnologias de informação e comunicação" (BRASIL, 2017) e que busca desenvolver "atividades educativas por estudantes e profissionais da educação que estejam em lugares e tempos diversos" (BRASIL, 2017). O decreto 
9.057/2007, no artigo $1^{\circ}$, prevê na EaD a utilização de tecnologias (elemento presente no ciberespaço) e a conexão de pessoas que não se encontram no mesmo lugar e tempo (novas formas de comunicação permitidas no ciberespaço).

Para se ter uma mudança qualitativa da aprendizagem, não basta digitalizar conteúdos dos cursos de formato presencial e inserir no ciberespaço, ou seja, fazer a transferência dos cursos já existentes para o formato com os recursos do ciberespaço (LÉVY, 1999). O autor conceitua cibercultura como um "conjunto de técnicas (materiais e intelectuais), de práticas, de atitudes, de modos de pensamento e de valores que se desenvolvem juntamente com o crescimento do ciberespaço" (LÉVY, 1999, p. 17).

Neste sentido, é necessário buscar uma educação que contemple as mudanças promovidas pelo ciberespaço, onde o professor deve promover a inteligência coletiva, adotando uma postura de mediador do aluno com o conhecimento e na relação com as tecnologias digitais. Esta postura docente é a mesma descrita na EaD, em que nos "novos 'campus virtuais', professores e estudantes partilham os recursos materiais e informacionais de que dispõem" propiciando que "professores aprendam ao mesmo tempo que os estudantes e atualizam continuamente tanto seus saberes 'disciplinares' como suas competências pedagógicas" (LÉVY, 1999, p. 171 - grifos do autor).

Dessa forma, não basta a presença das tecnologias digitais na educação; é necessário também se apropriar e ter uma identificação cultural com o uso das tecnologias digitais para promover um ensino que desenvolva nos alunos habilidades e competências para inserção no ciberespaço. Entendemos que a EaD, por trazer em sua definição elementos desse ciberespaço pode favorecer a apropriação do uso das tecnologias digitais.

Essa apropriação pode ser pensada com os conceitos da teoria de Bourdieu (1996), como capital cultural, campo e habitus. O capital cultural não é restrito ao capital adquirido na escola e recebe influência do meio social em que a pessoa está inserida e, assim, também compreende os costumes e cultura dos povos (PIES, 2012). Para Bourdieu (2007) o capital cultural existe sob três formas: no estado incorporado, no estado objetivado e no estado institucionalizado. O capital no estado incorporado é o capital que foi incorporado pelo sujeito e, por isso, é parte do corpo, um habitus, portanto, o "capital cultural é um ter que se tornou ser" (BOURDIEU, 2007, p. 74), ele não pode ser transmitido por doação e para ocorrer a incorporação é necessário investir tempo (BOURDIEU, 2007). O capital no estado objetivado é caracterizado pelos bens culturais, os quais podem ser transmitidos por doação, como, por exemplo, um software que pode ser baixado gratuitamente. No entanto, a posse não caracteriza apropriação do bem, pois para a apropriação ocorrer é necessário a posse do capital incorporado (Bourdieu, 2007). No estado institucionalizado, temos os certificados e diplomas como forma do reconhecimento institucional da posse de um determinado capital cultural (BOURDIEU, 2007).

O campo, outro conceito importante da obra de Bourdieu, se apresenta "como espaços estruturados de posições (ou de postos) cujas propriedades dependem da sua posição nesses espaços e que podem ser analisadas independentemente das características dos seus ocupantes" (BOURDIEU, 2003, p. 119). Para que o campo funcione, segundo Bourdieu (2003), necessitamos de objetos de disputas e pessoas dotadas de habitus dispostas a participar do jogo. Embora o campo seja um lugar de disputa, há elementos comuns aos seus participantes, os quais são aceitos como óbvios e que condicionam os ingressantes à sua aceitação, sob pena de exclusão do jogo, ou seja, impõem limites para a subversão da estrutura do campo (BOURDIEU, 2003).

Bourdieu usa o termo habitus como um conhecimento adquirido, algo incorporado pelo agente e o capital no estado incorporado relaciona-se ao habitus (BOURDIEU, 2007b). O autor define habitus como:

[...] sistemas de disposições duráveis, estruturas estruturadas predispostas a funcionar como estruturas estruturantes, isto é, como prin- 
cípio gerador e estruturador das práticas e das representações que podem ser objetivamente "reguladas" e "regulares" sem ser o produto da obediência a regras objetivamente adaptadas a seu fim, sem supor a intenção consciente dos fins e o domínio expresso das operações necessárias para atingi-los e coletivamente orquestradas, sem ser o produto da ação organizadora de um regente (BOURDIEU, 1983, 60-61).

O habitus determina as práticas do agente de modo harmonizadas, sem intenção de coerência, e também orquestradas, de forma inconsciente, com os demais membros da classe, como uma forma de senso prático. O habitus também é diferenciador, ou seja, quando agentes possuem capital diferente as práticas serão distintas (BOURDIEU, 1996; 2007b).

Para Bourdieu (1996), a partir do habitus, é possível prever grande parte das ações dos agentes devido as disposições adquiridas, assim o habitus possui como função descrever as práticas e bens de um agente ou de uma classe de agentes.

Pensando em como a teoria de Levy se aproxima de Bourdieu, entendemos ser possível estabelecer algumas relações do capital incorporado e objetivado com elementos da cibercultura. O capital incorporado, podemos relacionar com as práticas, atitudes e modos de pensamento (técnicas intelectuais), pois essas características da cibercultura estão incorporadas no indivíduo. Já as técnicas materiais, podemos classificar como capital objetivado, caracterizado, por exemplo, pelos softwares e hardwares.

O ciberespaço, ao mudar as estruturas sociais, age como um elemento que reorganiza os habitus dos agentes do campo. Ao restringirmos para o campo da EaD, constatamos a mudança de comportamento exigida de professores e alunos quando em comparação com sistemas tradicionais de educação. Na cibercultura, espera-se um modelo pedagógico no qual o professor age como condutor do aprendizado.

As mudanças impostas pela atual pandemia da Covid-19, por exemplo, revela exatamente como os agentes se viram obrigados a reestruturar as suas relações e incorporar novos habitus, exigindo do professor uma nova ação nesse contexto, colocando a EaD como um campo de aprendizagem.

\section{O percurso metodológico}

A presente pesquisa é de natureza quanti-qualitativa, pois faz uso de recursos da pesquisa quantitativa (baseado em informações numéricas, estatísticas), bem como utiliza de elementos da pesquisa qualitativa (na forma de textos obtidos por entrevistas ou questionários com respostas abertas (CRESWELL, 2007). As análises quantitativas e qualitativas podem ser combinadas para a análise dos resultados de pesquisas científicas, deixando de lado a mera oposição entre as duas análises. Dessa forma, temos a possibilidade de abordagem usando as duas metodologias, que pode ser denominada de pesquisa quanti-qualitativa ou de métodos mistos (CRESWELL, 2007).

Os dados foram coletados por meio de questionário eletrônico via Google Docs, cujo link com o convite para participar da pesquisa e rol de questões, foi enviado para 106 egressos do curso de Licenciatura em Matemática da modalidade EaD da Universidade Estadual de Ponta Grossa (UEPG); entretanto, tivemos a devolutiva de apenas 20 desses egressos².

Para organização e análise dos dados, utilizamos primeiramente a Análise Textual Discursiva (ATD)

2 Durante o momento em que a pesquisa foi realizada, os sujeitos participantes da pesquisa representavam em torno de 19\% dos egressos do curso de Licenciatura em Matemática na modalidade EAD da Universidade Estadual de Ponta Grossa (UEPG). A conclusão do curso para esses egressos foi entre os anos de 2013 e 2019. 
de Moraes e Galiazzi (2016), que se caracteriza por uma metodologia de análise qualitativa que permite uma leitura profunda dos textos obtidos nos questionários e entrevistas, e a compreensão do fenômeno investigado (PEREIRA, COSTA, LUNARDI, 2017; MORAES, GALIAZZI, 2016).

No Quadro 1, apresentamos as quatro etapas centrais da ATD (MORAES; GALIAZZI, 2016) e como estas foram aplicadas nesta pesquisa.

Quadro 1: Etapas da Análise Textual Discursiva (ATD)

\begin{tabular}{|l|l|}
\hline \multicolumn{1}{|c|}{ Etapas } & \multicolumn{1}{c|}{ Descrição das etapas } \\
\hline $\begin{array}{l}\text { 1. Desmontagem dos } \\
\text { textos ou unitarização }\end{array}$ & $\begin{array}{l}\text { Nesta etapa, primeiro organizamos os dados dos questionários em quadros } \\
\text { num documento no Word. Em cada quadro são colocadas as respostas de } \\
\text { uma pergunta do questionário. Após, realizamos a leitura dos questionários, } \\
\text { examinando os detalhes e fragmentando-os em unidades constituintes para } \\
\text { selecionar os trechos relevantes para a pesquisa. }\end{array}$ \\
\hline $\begin{array}{l}\text { 2. Estabelecimento } \\
\text { de relações ou } \\
\text { categorização }\end{array}$ & $\begin{array}{l}\text { Na segunda etapa, classificamos os trechos identificados na etapa anterior, } \\
\text { agrupando-os por semelhança das respostas e, reunimos os elementos } \\
\text { unitários de modo mais complexo. Para a categorização, identificamos o que } \\
\text { chamamos de "significantes elementares" de cada pergunta ou questão e, } \\
\text { em seguida, os agrupamos por semelhança semântica. }\end{array}$ \\
\hline $\begin{array}{l}\text { 3. Captação do novo } \\
\text { emergente }\end{array}$ & $\begin{array}{l}\text { Na terceira etapa, a partir da análise das etapas anteriores, buscamos "uma } \\
\text { compreensão renovada do todo" (MORAES; GALIAZZl, 2016, p. 34). Nesta } \\
\text { fase, nos detemos na análise dos significantes elementares para encontrar } \\
\text { sentido e realizar inferências sobre os dados coletados, a partir do referen- } \\
\text { cial teórico adotado. Nesta etapa, buscamos articular os resultados com a } \\
\text { teoria, estabelecendo um diálogo entre eles. }\end{array}$ \\
\hline $\begin{array}{l}\text { 4. Processo } \\
\text { auto-organizado }\end{array}$ & $\begin{array}{l}\text { As três etapas descritas anteriormente compõem um processo auto-orga- } \\
\text { nizado a partir do qual surge a compreensão sobre a temática da pesquisa. } \\
\text { A ATD compreende a sequência recursiva das três etapas anteriores, um } \\
\text { processo auto-organizado e se revela no momento de conclusão da investi- } \\
\text { gação realizada, com a produção de metatextos. }\end{array}$ \\
\hline
\end{tabular}

Fonte: os autores, com base em Moraes e Galiazzi (2016)

Após a categorização dos dados por meio da ATD, estes foram codificados e pré-analisados por meio de uma ferramenta quantitativa destinada à análise exploratória de dados denominada Análise de Clusters. Essa etapa foi programada e processada no ambiente do software Mathematica® pelo professor Dr. José Tadeu Teles Lunardi do Departamento de Matemática e Estatística da Universidade Estadual de Ponta Grossa (UEPG).

No Quadro 2 abaixo apresentamos o modelo do questionário que foi enviado aos egressos do Curso de Licenciatura em Matemática modalidade EaD da UEPG:

Quadro 2: Questões do Questionário respondidas pelos egressos e utilizadas na Análise de Clusters

\begin{tabular}{|l|}
\hline \multicolumn{1}{|c|}{ Questões } \\
\hline 1. Atividade Profissional \\
\hline 2. Qual (ou quais) a motivação para escolher um curso EaD? \\
\hline 3. Ao escolher o curso de Licenciatura em Matemática, você tinha como objetivo a carreira de professor? \\
\hline 4. Caso sua atividade profissional não seja como professor, cite o motivo que leva a isso. \\
\hline $\begin{array}{l}\text { 5. Possui ou está cursando outra graduação? Se possui outra graduação, ela foi feita em qual modali- } \\
\text { dade? A conclusão foi anterior ou posterior à Licenciatura em Matemática? }\end{array}$ \\
\hline
\end{tabular}


6. Como você percebe o uso da tecnologia no curso EaD de Licenciatura em Matemática? Consegue fornecer alguns exemplos?

Como a interatividade proporcionada pelas tecnologias digitais foram exploradas e usadas durante 0 curso? Consegue fornecer exemplos? Como isso foi incorporado na sua prática?

7. Houve diferença nas disciplinas do curso e o uso da tecnologia? De que forma?

8. Como era sua relação com a tecnologia antes de ingressar no curso EaD? A partir da realização do curso na modalidade EaD, você identifica mudanças no seu comportamento diante das tecnologias digitais? Como isso ocorre? Cite alguns exemplos.

9. Você percebe impacto das tecnologias digitais na sua prática docente? De que forma? De que forma a educação no contexto a distância contribui para a sua ação prática em sala de aula? Ou seja, como isso foi incorporado à sua prática docente?

10. Você acredita que a apropriação das tecnologias por alunos da modalidade EaD é maior que nos alunos formados em cursos presenciais? Como você justifica? Pode citar alguns exemplos?

11. Na sua formação, você teve orientações para o uso das tecnologias digitais em sala de aula? Como foram as orientações?

12. Você acredita que o uso das tecnologias digitais contribui para a educação? Quais as contribuições?

13 Você considera que quanto mais presentes as tecnologias digitais no curso, maior será o uso dos futuros professores quando estiverem em sala de aula?

Fonte: Os autores

No Quadro 3, apresentamos como foi organizada cada uma das etapas utilizadas para a realização da Análise de Clusters.

Quadro 3: Passos para Análise de Clusters (ACl)

\begin{tabular}{|l|l|}
\hline \multicolumn{1}{|c|}{ Etapa } & \multicolumn{1}{c|}{ Descrição } \\
\hline $\begin{array}{l}1^{\circ} \text { passo - Seleção dos } \\
\text { sujeitos da pesquisa }\end{array}$ & $\begin{array}{l}\text { Os sujeitos da pesquisa são 20 egressos do Curso de Licenciatura em } \\
\text { Matemática da UEPG, oferecido na modalidade EaD em parceria com o } \\
\text { Sistema UAB. }\end{array}$ \\
\hline $\begin{array}{l}2^{\circ} \text { passo - Seleção das } \\
\text { variáveis }\end{array}$ & $\begin{array}{l}\text { As variáveis são os "significantes elementares", identificados nas respos- } \\
\text { tas dos egressos que participaram da pesquisa, conforme descrito nos } \\
\text { passos 1 e 2 do Quadro 1. Os significantes elementares são identificados } \\
\text { e organizados a partir de um agrupamento de palavras ou expressões, } \\
\text { por significado semântico. Apresentamos no Quadro 5 um exemplo dos } \\
\text { significantes elementares. }\end{array}$ \\
\hline $\begin{array}{l}3^{\circ} \text { passo - Tratamento das } \\
\text { variáveis }\end{array}$ & $\begin{array}{l}\text { As variáveis identificadas no passo anterior são organizadas uma tabela } \\
\text { do Excel (conforme o exemplo da Figura 1) em forma de uma matriz } \\
\text { composta pelos sujeitos e pelos significantes elementares. A matriz é } \\
\text { organizada a partir dessas variáveis, agora transformadas em códigos } \\
\text { matemáticos (0' e 1') para processamento no programa Mathematica®. }\end{array}$ \\
\hline $\begin{array}{l}4^{\circ} \text { passo - Análise qualita- } \\
\text { tiva dos clusters gerados } \\
\text { na etapa anterior }\end{array}$ & $\begin{array}{l}\text { Após o processamento, são gerados os Clusters que serão objeto de } \\
\text { análise qualitativa. Neste momento, retornamos ao passo 4 do Quadro } \\
1 \text { para obter um olhar emergente desse processo e produzir o metatex- } \\
\text { to, conforme destacado por Moraes e Galiazzi (2016). }\end{array}$ \\
\hline
\end{tabular}

Fonte: Os autores.

Toda essa organização e tratamentos das respostas do questionário, a partir da ATD e da Análise de Clusters, nos ajudou a identificar as percepções dos egressos quanto ao uso das tecnologias e se estas revelam indícios de incorporação das tecnologias em suas práticas, que possam ser caracterizadas como um habitus. 
Para as respostas de cada pergunta, elaboramos um quadro com os significantes elementares, conforme exemplificamos no Quadro 4:

Quadro 5: Significantes Elementares

\begin{tabular}{|c|c|c|}
\hline Pergunta & Significantes elementares & Egressos \\
\hline \multirow{8}{*}{$\begin{array}{l}\text { 10. Você acredita que a } \\
\text { apropriação das tec- } \\
\text { nologias por alunos } \\
\text { da modalidade EaD é } \\
\text { maior que nos alunos } \\
\text { formados em cursos } \\
\text { presenciais? Como você } \\
\text { justifica? Pode citar } \\
\text { alguns exemplos? }\end{array}$} & A10 - Sim & $1,2,3,6,8,11,12,1314,16,17,18,20$ \\
\hline & B10 - Não & $4,5,7,9,10,15,19$ \\
\hline & $\begin{array}{l}\text { C10 - Uso constante das tecno- } \\
\text { logias no curso }\end{array}$ & $1,2,3,6,7,8,12,13,14,16,17,18,20$ \\
\hline & D10 - Interação & 3 \\
\hline & E10 - Aprendizado Sozinho & 11 \\
\hline & F10 - Exemplos durante curso & 14 \\
\hline & $\begin{array}{l}\text { G10 - Tecnologia está disponí- } \\
\text { vel para todos - basta buscar }\end{array}$ & $5,9,10,18$ \\
\hline & H10 - Particularidades do curso & $2,8,14,17$ \\
\hline
\end{tabular}

Fonte: Os autores

No Quadro 5, para cada pergunta, as letras indicam as variáveis (significantes elementares); assim, a pergunta 10 teve 8 variáveis (" $\mathrm{A}$ " à " $\mathrm{H}$ "), e após, fizemos uma planilha no Excel para representar os dados das respostas às questões. Na Figura 1, observamos as respostas às questões 8, 9 e 10 do Quadro 5 no formato de uma matriz. Nessa planilha, a coluna código representa os egressos do curso que responderam ao questionário (E1 ao E20). Já a linha código indica os significantes elementares, indicados pela letra, seguido do número que corresponde à pergunta do questionário (Quadro 2). Para as respostas, organizadas por meio da ATD, foi atribuído um código binário, "0" ou "1", para permitir que o software realize a comparação. O código binário "1" indica a presença do significante elementar na resposta do egresso e a ausência é representada pelo código " 0 ".

Figura 1: Exemplo de codificação das respostas ao questionário

\begin{tabular}{|c|c|c|c|c|c|c|c|c|c|c|c|c|c|c|c|c|c|c|c|c|}
\hline Código & A8 & B8 & C8 & D8 & E8 & F8 & G8 & A9 & B9 & C9 & D9 & E9 & A10 & B10 & C10 & D10 & E10 & F10 & G10 & H10 \\
\hline E1 & 1 & 0 & 0 & 1 & 0 & 1 & 0 & 0 & 1 & 0 & 0 & 0 & 1 & 0 & 1 & 0 & 0 & 0 & 0 & 0 \\
\hline E2 & 0 & 1 & 0 & 1 & 0 & 1 & 0 & 0 & 1 & 0 & 1 & 0 & 1 & 0 & 1 & 0 & 0 & 0 & 0 & 1 \\
\hline E3 & 1 & 0 & 0 & 0 & 1 & 1 & 0 & 0 & 1 & 0 & 1 & 0 & 1 & 0 & 1 & 1 & 0 & 0 & 0 & 0 \\
\hline E4 & 0 & 0 & 1 & 0 & 1 & 0 & 0 & 1 & 0 & 0 & 0 & 0 & 0 & 1 & 0 & 0 & 0 & 0 & 0 & 0 \\
\hline E5 & 1 & 0 & 0 & 0 & 1 & 1 & 0 & 1 & 0 & 0 & 0 & 0 & 0 & 1 & 0 & 0 & 0 & 0 & 1 & 0 \\
\hline E6 & 0 & 1 & 0 & 1 & 0 & 0 & 1 & 0 & 1 & 0 & 1 & 0 & 1 & 0 & 1 & 0 & 0 & 0 & 0 & 0 \\
\hline
\end{tabular}

Fonte: Os autores

A partir dessa matriz numérica, o Mathematica ${ }^{\circledR}$ é programado para calcular a distância de correlação entre cada linha da matriz, ou seja, entre cada uma das respostas dos sujeitos, e assim gerar os Clusters. Observando a Figura 1, notamos que o egresso E1 possui resposta positiva para os significantes A8, D8 e F8 (por isso, codificamos com "1"), o que significa que a resposta do sujeito se enquadra nas categorias mencionadas e negativa para os outros significantes da questão 8 (por isso codificamos com “ 0 "), ou seja, quando a resposta não se adéqua à categoria. 
O termo Clusters, em inglês, significa aglomerados, agrupamentos, e a clusterização está relacionada a técnicas exploratórias de organização e análise de dados cujo objetivo é agrupar um conjunto de objetos em subconjuntos ou subgrupos denominados de clusters. Essa organização, ou agrupamento, se dá a partir de critérios de similaridade ou dissimilaridade entre os mesmos. Portanto, sujeitos e ou objetos que compõem um mesmo cluster, são agrupados por possuírem aspectos similares ou dissimilares entre si do que objetos agrupados em clusters diferentes.

A partir dessa matriz numérica, o Mathematica ${ }^{\circledR}$ é programado para calcular a distância de correlação entre cada linha da matriz, ou seja, entre cada uma das respostas dos sujeitos e assim gerar os Clusters, que gera um relatório com os dados de cada cluster e a "árvore hierárquica" ou "dendrograma" (Figura 2), que representa a organização dos Clusters da pesquisa:

Figura 2: Árvore hierárquica de Clusters ou Dendrograma

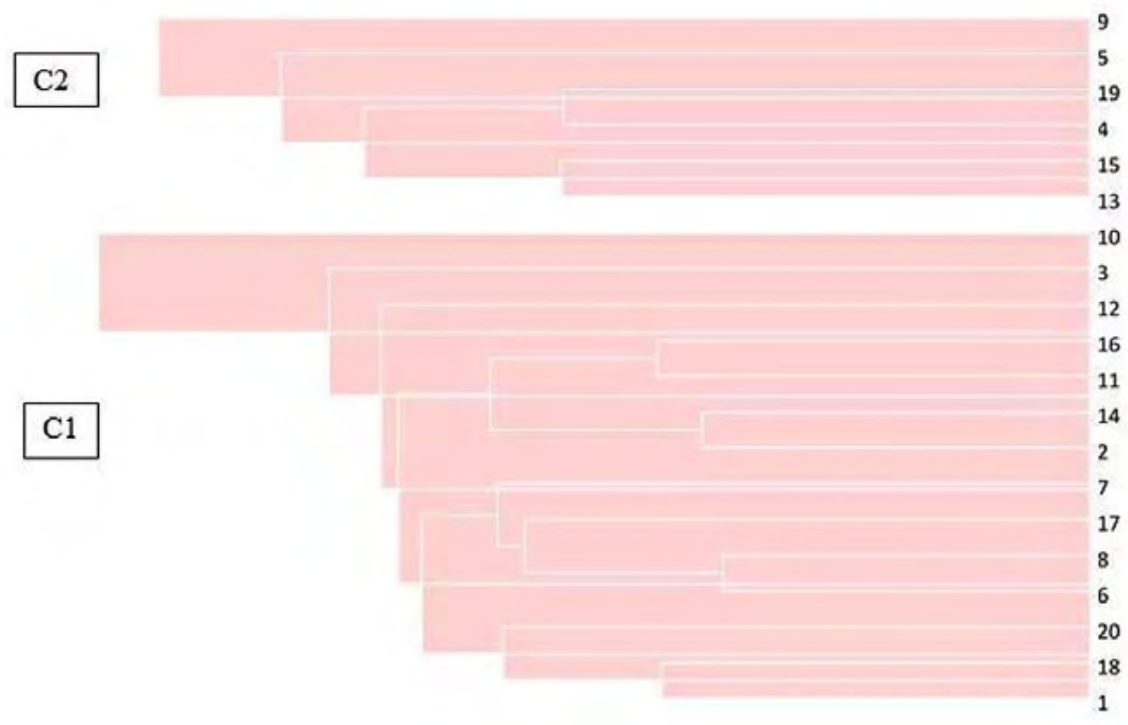

Fonte: os autores.

Obtivemos 2 clusters de egressos: o Cluster 1 agrupou 14 egressos (E1; E2; E3; E6; E7; E8; E10; E11; E12; E14; E16; E17; E18; E20) e o Cluster 2 agrupou 6 egressos (E4; E5; E9; E13; E15; E19).

Na próxima seção, apresentamos as discussões em relação a esses Clusters, buscando identificar as percepções sobre o uso das tecnologias digitais na prática dos egressos. Entendemos que o uso dos Clusters é uma ferramenta relevante na análise dos dados, pois evidenciam semelhanças e diferenças entre os grupos para além do que seria perceptível em um primeiro momento.

\section{Resultados e Discussões}

Passamos agora a apresentar nossos resultados e análises geradas a partir de cada cluster organizado pelos dados coletados via questionário. Na medida em que formos apresentando os dados, realizaremos as discussões dos mesmos, buscando relacioná-los com referenciais teóricos que podem contribuir com a análise dos mesmos. 


\subsection{Cluster 1}

No Quadro 6, apresentamos os significantes elementares, com as respectivas frequências, que se destacam no Cluster 1. Indicamos no quadro apenas os significantes elementares com frequência superior a $20 \%$.

Quadro 6: Significantes elementares predominantes no Cluster 1

\begin{tabular}{|c|c|c|c|}
\hline Categoria & Código & Significante elementar & Frequência \\
\hline \multirow{3}{*}{ Atividade profissional } & $\mathrm{A} 1$ & Outra atividade no setor público & 35,7 \\
\hline & B1 & Professor da educação básica da rede pública & 57,1 \\
\hline & E1 & Outras/Sem atividade formal & 21,4 \\
\hline \multirow{4}{*}{ Motivação } & $\mathrm{A} 2$ & Horário & 78,5 \\
\hline & B2 & Maternidade & 21,4 \\
\hline & $\mathrm{C} 2$ & Estudar sozinho/comprometimento/autonomia & 21,4 \\
\hline & E2 & Oportunidade/Gratuidade & 21,4 \\
\hline Objetivo professor & A3 & Sim & 100 \\
\hline \multirow{2}{*}{ Razão não ser professor } & A4 & Possui outro emprego & 28,5 \\
\hline & B4 & $\begin{array}{l}\text { Deseja atuar na docência, porém falta } \\
\text { oportunidade }\end{array}$ & 21,4 \\
\hline \multirow{6}{*}{$\begin{array}{l}\text { Possui ou está cursando } \\
\text { outra graduação }\end{array}$} & A5 & Sim & 71,4 \\
\hline & B5 & Não & 28,5 \\
\hline & C5 & $\mathrm{EaD}$ & 35,7 \\
\hline & D5 & Presencial & 42,8 \\
\hline & E5 & Anterior & 57,1 \\
\hline & F5 & Posterior & 21,4 \\
\hline \multirow{10}{*}{$\begin{array}{l}\text { Percepção do uso de tec- } \\
\text { nologia no curso }\end{array}$} & B6 & Importante & 64,2 \\
\hline & C6 & Interação & 64,2 \\
\hline & D6 & Webconferência & 64,2 \\
\hline & E6 & Fórum & 78,5 \\
\hline & F6 & Vídeo & 21,4 \\
\hline & G6 & Moodle & 28,5 \\
\hline & H6 & Comunicação via internet & 35,7 \\
\hline & J6 & Tarefas / questionários & 21,4 \\
\hline & K6 & Softwares & 28,5 \\
\hline & L6 & Arquivos & 21,4 \\
\hline \multirow{4}{*}{$\begin{array}{l}\text { Percebeu diferença nas } \\
\text { disciplinas em relação às } \\
\text { tecnologias }\end{array}$} & A7 & Sim & 71,4 \\
\hline & $\mathrm{C7}$ & Variedades de recursos tecnológicos & 50 \\
\hline & D7 & Domesticação & 21,4 \\
\hline & F7 & Softwares & 35,7 \\
\hline
\end{tabular}




\begin{tabular}{|l|c|l|c|}
\hline \multirow{4}{*}{$\begin{array}{l}\text { Relação com tecnologia } \\
\text { antes do curso }\end{array}$} & A8 & Boa & 42,8 \\
\cline { 2 - 4 } & B8 & Pouca & 50 \\
\cline { 2 - 4 } & D8 & Mudou comportamento & 78,5 \\
\cline { 2 - 4 } & F8 & Incorporou (indícios) & 78,5 \\
\hline \multirow{2}{*}{$\begin{array}{l}\text { Impacto tecnologias práti- } \\
\text { ca docente }\end{array}$} & B9 & Tem impacto & 85,7 \\
\cline { 2 - 4 } & D9 & EaD contribui & 64,2 \\
\hline \multirow{4}{*}{$\begin{array}{l}\text { Apropriação tecnologias } \\
\text { alunos EaD }\end{array}$} & A10 & Sim & 85,7 \\
\cline { 2 - 4 } & C10 & Uso constante das tecnologias no curso & 85,7 \\
\cline { 2 - 4 } & H10 & Particularidades do curso & 28,5 \\
\hline \multirow{3}{*}{$\begin{array}{l}\text { Orientações, no curso, so- } \\
\text { bre como usar tecnologias }\end{array}$} & A11 & Sim & 100 \\
\cline { 2 - 4 } & C11 & Softwares/internet & 42,8 \\
\cline { 2 - 4 } & D11 & Disciplinas específicas que trataram o assunto & 28,5 \\
\hline \multirow{4}{*}{$\begin{array}{l}\text { Tecnologia contribui para } \\
\text { educação }\end{array}$} & A12 & Sim & 100 \\
\cline { 2 - 4 } & C12 & Inovação/exploração & 42,8 \\
\cline { 2 - 4 } & D12 & Facilita/motiva & 64,2 \\
\cline { 2 - 4 } & E12 & Pesquisa & 100 \\
\cline { 2 - 4 } & H12 & Presença das tecnologias & 35,7 \\
\hline $\begin{array}{l}\text { Presença da tecnologia } \\
\text { no curso influencia uso na } \\
\text { prática docente }\end{array}$ & A13 & Sim & \\
\hline
\end{tabular}

Fonte: os autores.

Como podemos perceber, os participantes da pesquisa agrupados no Cluster 1 tinham como objetivo a carreira de professor ao término do curso. Podemos observar ainda que a EaD e o sistema de educação aberta propiciam ao aluno algumas flexibilidades para estudar. Os egressos do Cluster 1 evidenciam alguns aspectos nesse sentido para a escolha de um curso da UAB na modalidade a distância. Podemos observar esses aspectos nos exemplos de falas dos egressos 14 e 2 abaixo:

E14 - Por ter a possibilidade de estudar com horários flexíveis, um dia posso de manhã, em outro dia à tarde, a maioria das vezes durante o curso de Matemática estudava de madrugada.

E2 - A possibilidade de estudar sozinha e em casa.

Podemos perceber que a flexibilidade do horário e o fato do estudo solitário, corroboram com o perfil do aluno EaD como gestor da própria aprendizagem. No tocante à percepção dos egressos sobre o uso da tecnologia no curso, a maioria deles relatou a importância do seu uso. Essa questão pode ser observada nos exemplos de falas abaixo:

E20 - Sem a tecnologia, simplesmente não existiria a EaD, em tudo dependíamos dela.

E7 - Muito útil, tive facilidade em utilizar todos os recursos apresentados.

As tecnologias digitais e a internet possibilitaram um novo impulso para EaD, como desenvolvimento de Ambiente Virtual de Aprendizagem, comunicação em tempo real (mesmo com os agentes em locais distintos). Como vimos anteriormente, esses conceitos estão presentes no contexto do ciberespaço definido por Lévy (1999). Além disso, podemos destacar também a questão da interatividade como uma marca da EaD e os relatos dos egressos abaixo evidenciam a sua presença durante o curso: 
E17 - [...] as interações eram feitas via chat, fóruns, até mesmo de maneiras informais, como em redes sociais e e-mail.

E11 - [...] com o decorrer do curso e as dificuldades aumentando, começamos a nos comunicar pelas redes sociais.

Alguns egressos também relataram que o uso das tecnologias digitais, aprendidas no curso, faz parte da sua atual prática docente, como podemos observar nos exemplos de falas abaixo.

E18 - Alguns aprendizados utilizo em minha prática, como softwares de geometria, como Geogebra, CarMetal, e alguns outros.

E7 - Na graduação, foi apresentada ao Geogebra que, além de realizar o curso, continuo atuando como monitora voluntária e é uma ferramenta que utilizo em sala de aula com meus alunos.

O Cluster 1 reuniu egressos que antes do curso estavam habituados com o uso das tecnologias digitais, bem como, outros não tinham tanta familiaridade. Podemos destacar ainda que os egressos do Cluster 1 perceberam mudança no comportamento, em relação ao uso das tecnologias digitais; após o curso de graduação, podemos destacar os exemplos de falas abaixo:

E7 - Possibilitou conhecer software que eu não conhecia antes e ampliar ainda mais o gosto pelas tecnologias, tanto que procuro utilizá-las na escola quando possível.

E11 - Perdi o medo de conhecer novas tecnologias; pelo contrário, quero ficar cada vez mais atualizada.

Quanto à percepção dos egressos sobre a apropriação das tecnologias digitais, a maioria considera ser maior na formação no contexto EaD do que em relação aos cursos presenciais. A maioria justifica isso por conta do uso constante de tecnologias digitais durante o curso. Essa questão pode ser observada no exemplo de fala abaixo:

E2 - O aluno na modalidade EaD faz uso das tecnologias com maior frequência, pois sua sala de aula é virtual, utiliza todos os recursos digitais que lhe são oferecidos para atender as suas necessidades.

Na sequência, apresentamos os dados e discussões referentes ao Cluster 2.

\subsection{Cluster 2}

No Quadro 7, abaixo, apresentamos os significantes elementares que se destacam no Cluster 2:

Quadro 7: Significantes elementares predominantes no Cluster 2

\begin{tabular}{|l|c|l|c|}
\hline \multicolumn{1}{|c|}{ Categoria } & Código & \multicolumn{1}{|c|}{ Significante elementar } & Frequência \\
\hline Atividade profissional & A1 & Outra atividade no setor público & 66,6 \\
\hline \multirow{2}{*}{ Motivação } & D2 & Praticidade/Mobilidade & 50 \\
\cline { 2 - 4 } & E2 & Oportunidade/Gratuidade & 33,3 \\
\hline Objetivo ser professor & B3 & Não & 100 \\
\hline Razão não ser professor & A4 & Possui outro emprego & 83,3 \\
\hline
\end{tabular}




\begin{tabular}{|c|c|c|c|}
\hline \multirow{3}{*}{$\begin{array}{l}\text { Possui ou está cursando } \\
\text { outra graduação }\end{array}$} & A5 & Sim & 100 \\
\hline & D5 & Presencial & 66,6 \\
\hline & F5 & Posterior & 83,3 \\
\hline \multirow{6}{*}{$\begin{array}{l}\text { Percepção do uso de } \\
\text { tecnologia no curso }\end{array}$} & B6 & Importante & 33,3 \\
\hline & D6 & Webconferência & 33,3 \\
\hline & F6 & Vídeo & 33,3 \\
\hline & J6 & Tarefas / questionários & 33,3 \\
\hline & K6 & Softwares & 50 \\
\hline & L6 & Arquivos & 33,3 \\
\hline $\begin{array}{l}\text { Percebeu diferença nas } \\
\text { disciplinas em relação às } \\
\text { tecnologias }\end{array}$ & A7 & Sim & 66,6 \\
\hline \multirow{5}{*}{$\begin{array}{l}\text { Relação com tecnologia } \\
\text { antes do curso }\end{array}$} & B8 & Pouca & 50 \\
\hline & C8 & Normal/indiferente & 33,3 \\
\hline & D8 & Mudou comportamento & 66,6 \\
\hline & E8 & Não mudou & 33,3 \\
\hline & F8 & Incorporou (indícios) & 50 \\
\hline \multirow{2}{*}{$\begin{array}{l}\text { Impacto tecnologias } \\
\text { prática docente }\end{array}$} & A9 & Não se aplica & 66,6 \\
\hline & B9 & Tem impacto & 33,3 \\
\hline \multirow{2}{*}{$\begin{array}{l}\text { Apropriação tecnologias } \\
\text { alunos EaD }\end{array}$} & B10 & Não & 83,3 \\
\hline & G10 & $\begin{array}{l}\text { Tecnologia está disponível para todos - basta } \\
\text { buscar }\end{array}$ & 33,3 \\
\hline \multirow{3}{*}{$\begin{array}{l}\text { Orientações, no curso, } \\
\text { sobre como usar } \\
\text { tecnologias }\end{array}$} & A11 & Sim & 50 \\
\hline & B11 & Não & 50 \\
\hline & $\mathrm{F} 11$ & Teórico/básico & 33,3 \\
\hline \multirow{4}{*}{$\begin{array}{l}\text { Tecnologia contribui } \\
\text { para educação }\end{array}$} & A12 & Sim & 66,6 \\
\hline & B12 & Depende & 33,3 \\
\hline & $\mathrm{F} 12$ & Há ressalvas & 33,3 \\
\hline & $\mathrm{H} 12$ & Presença das tecnologias & 33,3 \\
\hline \multirow{2}{*}{$\begin{array}{l}\text { Presença da tecnologia } \\
\text { no curso influencia uso na } \\
\text { prática docente }\end{array}$} & A13 & Sim & 66,6 \\
\hline & B13 & Não & 33,3 \\
\hline
\end{tabular}

Fonte: Os autores

Observando e analisando os significantes do Cluster 2, podemos destacar que diferente do Cluster 1 , $100 \%$ dos egressos agrupados nesse cluster, fizeram o curso sem a intenção de exercer o ofício docente. Vemos, a partir dos clusters, outras similaridades nos integrantes de cada grupo, como em relação à percepção do uso das tecnologias digitais no curso, bem como a apropriação do uso delas pelos egressos da EaD.

Os egressos do Cluster 2 indicam o fato de possuírem outro emprego como justificativa para não seguir a carreira de professor. Essa questão pode ser evidenciada nos exemplos de falas abaixo: 
E4 - Sempre amei matemática, contudo já tenho uma carreira, entretanto dou aulas particulares e aulas para concursos públicos civis e militares.

Para os egressos do Cluster 2, no tocante à percepção do uso da tecnologia no curso, vemos uma porcentagem baixa; entretanto alguns egressos destacaram a importância do uso das tecnologias digitais como exemplo da fala do E5 abaixo:

E5 - A plataforma Moodle é incrível e atende as necessidades básicas do estudante de curso EaD.

Neste grupo de egressos, observamos que eles consideram que não há uma maior apropriação das tecnologias digitais por parte dos alunos da EaD. Alguns defendem que isso depende da atitude de cada aluno em buscar formas de usar as tecnologias, como afirma E5:

E5 - Quem tem real interesse em aprender procura recursos e informações onde for necessário.

Em relação ao uso da tecnologia antes do curso, os dados indicam que $50 \%$ dos egressos do cluster 2 tinham pouca relação e 33,3\% classificaram a relação como normal ou indiferente. Mas observamos que a maioria, 66,6\%, indicou mudança de comportamento na relação com a tecnologia após a realização do seu curso de formação de professores.

Podemos observar que no Cluster 2, 5 (cinco) egressos (83,3\%) responderam que não acreditam que a incorporação do uso da tecnologia seja maior na modalidade EaD. Há nas respostas indícios de incorporação do uso das tecnologias em 3 (três) egressos; desses, 2 apontam que há a contribuição do curso e outro atribui ao gosto pelas tecnologias. Nesse grupo, um dos egressos indicou ser professor, no entanto, não pudemos perceber indícios de incorporação do uso de tecnologia na sua prática docente, embora tenha apresentado mudança de comportamento em relação à tecnologia. Podemos inferir que essa visão diferenciada e esse distanciamento em relação ao uso das tecnologias para os egressos desse cluster se justifica principalmente, porque não atuam como professores e, por isso, essa construção ocorreu de forma diferente.

Analisando o Cluster 1 podemos destacar que 12 (doze) egressos declaram acreditar que há uma apropriação muito maior no uso das tecnologias pelos alunos na modalidade EaD quando comparado com alunos que se formam na modalidade presencial. Além disso, observando a fala deles, podemos destacar que na fala de 11 (onze) é possível identificar indícios de incorporação das tecnologias na prática.

Essas diferenças sobre a apropriação do uso das tecnologias apontadas nos dois clusters nos remetem para Lemos e Lévy (2010), quando destacam que a inclusão digital pressupõe fatores econômicos, cognitivos, social, intelectual e técnico. Segundo os autores, para que ocorra a inclusão, não basta a posse do bem tecnológico ou o conhecimento técnico, que envolve apenas um saber sobre usar um equipamento ou software; é necessário que haja transformação da informação em conhecimento e a sua utilização implique apropriação de um saber. Assim, uma formação ao privilegiar o conhecimento técnico não garante a inclusão; é necessário desenvolvimento cognitivo para transformar a utilização em apropriação, isso pode ser mais evidenciado no Cluster 1, por exemplo, do que no Cluster 2.

Essas tecnologias digitais, enquanto bem (equipamentos e softwares) e como elementos do ciberespaço apontado por Lévy (1999), podem ser consideradas como capital no estado objetivado na teoria de Bourdieu. De forma semelhante, Bourdieu (2007) defende que o capital objetivado será ativo e atuante quando incorporado, ou seja, não basta apenas a aquisição dos bens, é necessária uma apropriação criativa.

Nessa pesquisa, buscamos elementos para constatar a transformação da utilização da tecnologia em apropriação a partir de saber evidenciado por meio de um habitus. Entendemos que a análise de Clusters e os relatos dos egressos, nos permitem inferir que houve indícios dessa incorporação nos egressos do cluster 1, pois o uso das tecnologias digitais não ficou restrito ao curso de graduação, mas revelam indí- 
cios da incorporação desse uso como parte da sua prática docente. Observamos ainda que há influência do curso na busca por mais conhecimentos, pois os egressos desse cluster revelaram uma identificação maior com aspectos da sua formação realizada na modalidade em EaD, como a autonomia do aprendizado e a crença de que os recursos tecnológicos podem favorecer o aprendizado.

Embora 66\% dos egressos do Cluster 2 tenham dito que a presença da tecnologia no curso influencia o seu uso na prática docente e que contribui para a educação, parece-nos que eles não construíram uma relação tão próxima com o uso da mesma a ponto de evidenciar uma apropriação que pudesse ser configurada como um indício de habitus, mesmo que seja na sua atual profissão. Podemos inferir que, para os egressos desse cluster, o uso da tecnologia ficou à margem do que Lemos e Lévy (2010) chama de "bem tecnológico ou o conhecimento técnico", já que não encontamos indícios de incorporação do uso da mesma como um habitus. Acreditamos que esses egressos tenham adquirido alguns capitais, que vão além do capital cultural relacionado com a conquista do seu diploma. $O$ fato de não terem revelado indícios de incorporação de habitus em relação ao uso das tecnologias na sua prática e terem construído outra relação com as tecnologias, pode estar atrelado à questão do campo apresentada por Bourdieu (2007), já que no cluster $2,100 \%$ dos egressos atuam em outras áreas e optaram por não atuar no campo educacional.

\section{Considerações finais}

O propósito inicial em nossa investigação foi de apresentar o resultado de uma pesquisa que teve como objetivo desvelar se, e como, os professores formados no contexto EaD se apropriam do uso das tecnologias digitais na sua prática de forma a constituir um habitus. Por meio de Análise Textual Discursiva e Análise de Clusters, identificamos dois clusters. Uma característica importante evidenciada em cada cluster foi em relação ao desejo ou não de ser professor. O primeiro cluster mostra a aproximação dos egressos que fizeram o curso com o intuito de ser professor. No segundo cluster, foram agrupados os egressos que não tinham o desejo de exercer a profissão docente, e todos os egressos já exercem outra atividade profissional e tiveram no curso da UAB a possibilidade de concluir uma graduação.

Os dois agrupamentos indicam percepções diferentes em relação ao curso e ao uso das tecnologias digitais. Em relação à apropriação do uso das tecnologias digitais, foi possível evidenciar que esta foi maior para os egressos do Cluster 1 do que para os do Cluster 2. Nossos resultados nos permitem inferir ainda que essa apropriação está relacionada à percepção que os egressos têm do processo de formação na modalidade EaD, visto que os egressos do Cluster 1 indicaram acreditar muito mais nesse processo e na contribuição das tecnologias digitais para a educação do que os egressos do Cluster 2. Também o exercício da docência vivenciado pelos egressos do cluster 1 pode influenciar nessa apropriação, já que ambos atuam em campos diferentes. No relato dos egressos do cluster 1 , percebemos ainda o reconhecimento da importância do uso das tecnologias digitais - fato que pode implicar uma prática docente na qual o seu uso encontra-se presente, compreendendo as mudanças no ensinar e aprender que as tecnologias ocasionam.

A análise dos clusters evidenciam que os professores formados no contexto EaD se apropriam do uso das tecnologias digitais na sua prática docente de forma a constituir um habitus. Entretanto, o como isso é apropriado foi evidenciado de forma diferente em cada um dos clusters. Isso pode ser evidenciado no cluster 1 de uma forma mais profunda do que no cluster 2, e acreditamos que esse fato esteja relacionado ao exercício da docência, pois, ao atuar nesse campo, o egresso pode fazer um uso maior das tecnologias e se apropriar mais desses saberes.

Parece-nos ainda que há aspectos diferentes no perfil do aluno EaD, como gestor da própria aprendizagem, e que promove disposições duráveis nos egressos, e funcionam como princípio gerador de práticas que refletem o uso das tecnologias digitais. Esse é um aspecto que buscaremos explorar em uma próxima pesquisa! 


\section{Agradecimentos}

Os autores agradecem ao professor Dr. José Tadeu Teles Lunardi, do Departamento de Matemática e Estatística (UEPG), pela ajuda na programação e processamento dos dados no software Mathematica ${ }^{\circledR}$ (Wolfram Language).

A autora ALP agradece à Fundação Araucária/PR pela bolsa produtividade em pesquisa.

\section{Referências}

ALVES, J. R. M. A História da EaD no Brasil. In: LITTO, F.; FORMIGA, M. (Org.). Educação a distância: o estado da arte. 1. ed. São Paulo: Pearson Education do Brasil, v. 1, 2009. 9-14 p. Disponível em: <http:// www.abed.org.br/arquivos/Estado da Arte 1.pdf>. Acesso em: 20 nov. 2018.

BOURDIEU, P. Esboço de uma teoria da prática. In: Ortiz, Renato (Org.). Pierre Bourdieu. São Paulo: Ática. p. 46-81. 1983.

BOURDIEU, P. Razões práticas: sobre a teoria da ação. Campinas: Papirus, 1996.

BOURDIEU, P. Algumas propriedades do campo. In: BOURDIEU, P. Questões de sociologia. Tradução de Miguel Serras Pereira. Fim de Século: Lisboa, 2003, p. 119-126.

BOURDIEU, P. Os três estados do capital cultural. In: NOGUEIRA, M. A.; CATANI, A. M. (Org.). Escritos de educação. Tradução de Aparecida Joly Gouveia. 9. ed. Petrópolis: Vozes, 2007a. p. 71-80

BOURDIEU, P. A distinção: crítica social do julgamento. São Paulo: Edusp; Porto Alegre: Zouk, $2007 \mathrm{~b}$.

BRASIL. Decreto $\mathbf{n}^{\circ} \mathbf{8 . 8 0 0}$, de $\mathbf{8}$ de junho de 2006. Dispõe sobre o Sistema Universidade Aberta do Brasil - UAB, 2006. Disponível em: <http://www.planalto.gov.br/ccivil 03/Ato2004-2006/2006/Decreto/ D5800.htm>. Acesso em: 24 ago. 2018.

BRASIL. REFERENCIAIS DE QUALIDADE PARA EDUCAÇÃO SUPERIOR A DISTÂNCIA, ago. 2007. Disponível em: <http://portal.mec.gov.br/seed/arquivos/pdf/legislacao/refEaD1.pdf>. Acesso em: 23 ago. 2018.

BRASIL. Decreto n 9.057, de 25 de maio de 2017. Regulamenta o art. 80 da Lei $n^{\circ}$ 9.394, de 20 de dezembro de 1996, que estabelece as Diretrizes e Bases da Educação Nacional, 2017. Disponível em: <http:// www.planalto.gov.br/ccivil_03/_Ato2015-2018/2017/Decreto/D9057.htm>. Acesso em: 04 ago. 2019.

CRESWELL, J. W. Projeto de Pesquisa: Método qualitativo, quantitativo e misto. 2. ed. Porto Alegre: Artmed, 2007.

LEMOS, A; LÉVY, P. O futuro da internet: em direção a uma ciberdemocracia planetária. São Paulo: Paulus, v. 13, 2010.

LÉVY, P. Cibercultura. Tradução de Carlos Irineu da Costa. $1^{\text {a }}$ Ed. São Paulo: Ed. 34, 1999.

LÉVY, P. O ciberepaço como um passo metaevolutivo. Revista FAMECOS: mídia, cultura e tecnologia, Porto Alegre, n. 13, p. 59-67, Dezembro 2000. Disponível em: <http://revistaseletronicas.pucrs.br/ojs/index.php/revistafamecos/article/view/3081>. Acesso em: 29 jul. 2019.

LÉVY, P. A inteligência coletiva: por uma antropologia do ciberespaço. Tradução de Luiz Paulo Rouanet. São Paulo: Loyola, 2015. 
MORAES, R.; GALIAZZI, M. D. C. Análise textual discursiva. 3. ed. Ijuí: Unijuí, 2016.

PEREIRA, A. L.; COSTA, C.; LUNARDI, J. T. Cluster analysis characterization of research trends connecting social media to learning in the United Kingdom. Revista de Produtos Educacionais e Pesquisas em Ensino REPP, Cornélio Procópio, v. 1, n. 1, p. 48-58, 2017.

PEREIRA, A. L., LUNARDI, J. T. T. Análise de Clusters: uma análise a partir de pesquisas na área de ensino e educação. (No prelo).

PIES, N. Processo educacional em Pierre Bourdieu. Revista Espaço Acadêmico, v. 12, n. 134, p. 40-46, JuIho 2012. Disponível em: <http://periodicos.uem.br/ojs/index.php/EspacoAcademico/article/view/17688>. Acesso em: 24 jul. 2018.

PONTE, J. P. Tecnologias de informação e comunicação na educação e na formação de professores: Que desafios? Revista Ibero-Americana de Educação, n. 24, p. 63-90. Disponível em: <http://www.educ. fc.ul.pt/docentes/jponte/docs-pt/00-Ponte-TIC\%20(rie24a03).pdf>. Acesso em: 23 jun. 2019.

ZABEL, M., \& ALMEIDA, H. Um retrato da formação online do Professor de Matemática. As Licenciaturas em Matemática da Universidade Aberta do Brasil (UAB): uma visão a partir da utilização das Tecnologias Digitais. São Paulo: Livraria da Física, 2015. 